\title{
The usefulness of distinguishing types of aggression by function*
}

\section{J. Martín Ramírez}

Problems of aggression and violence are widespread and affect interpersonal relationships, inter-group interactions and society in general. It is therefore important to better understand human aggression by carrying out more in-depth studies of the complex dynamics that exist between biological variables (genes, biochemistry, neural circuits), personality factors and environmental circumstances that influence the development and expression of aggression (Nelson and Trainor 2007).

To better understand a phenomenon - aggression and violence, for example we first need to formulate a working definition that is as precise as possible and establishes a consensus on what is under discussion; on the differences that may exist between violence and aggression; their causes and mechanisms, and their possible consequences. For example, it should be decided whether violence is completely unavoidable or, to the contrary, avoidable, as declared in the Seville Statement on Violence (Adams et al. 1986) adopted by the
J. Martín Ramírez heads the Research Group on the Sociopsychobiology of Aggression, Institute of Biofunctional Studies and Psychobiology Department, Universidad Complutense de Madrid.

His main areas of research include aggression in a wide range of animal species (from an interdisciplinary perspective), in humans (from a cross-cultural perspective) and in a wide variety of cultures in Europe, Asia, Africa and North America. Professor Ramírez also studies the underlying psychological processes involved in various forms of aggression, with a special focus on sexual dimorphism; the moderating role of different contexts that predispose towards and are associated with violence. Professor Ramírez has recently researched political violence and terrorism, being research fellow with the International Security Programme, Belfer Centre for Science and International Affairs, Kennedy School of Government at Harvard University and at the Hoover Institution on War, Revolution and Peace, Stanford University.

Related publications include J. Martin Ramírez, The Ulster Peace Process as an experience of peacebuilding, in Behavioral Sciences on Terrorism and Violence, 3(1), 2011, 72-76; Daniel Antonius, Adam D. Brown, Tali K. Walters, J. Martin Ramirez and Samuel Justin Sinclair (eds) Interdisciplinary Analyses of Terrorism, Cambridge Scholars Publishing (2010) and J. Martin Ramírez (2009) Some dichotomous classifications of aggression according to its function, in Journal of Organisational Transformation and Social Change 6(2), 85-101; J. Martin Ramírez, (2007) Peace through dialogue in International Journal on World Peace, 24(1), 65-81 and J. Martin Ramírez, (2007). Justification of aggression in several Asian and European countries with different religious and cultural background in International Journal of Behavioral Development, 31(1),: 9-15.

Email: mramirez@med.ucm.es

www: http://www.jmartinramirez.org
General Conference of UNESCO in 1989, or whether certain acts of aggression are justifiable in specific circumstances or always unacceptable; a topic researched by the author and colleagues in very diverse cultures (Ramírez 1991, 1993, 2007b).

Clarification is still needed on the conceptual difference between aggression and violence. Many authors, in an attempt to present the two along a continuum, tend to establish violence as an extreme form of aggression. Ample contexts exist, however, in which aggression is seen, on the contrary, as more serious and punishable than mere violence, such as in cases judged by committees on violence in sport or studies on aggression in the media, where attacks on inanimate objects are classified as violence (for instance, the burning of cars or homes and the destruction of property), but the concept of aggression is often limited to attacks on people.

Other authors, using the dichotomy identified 
by Erich Fromm (1973), present aggression and violence as two opposing biological concepts. Fromm distinguishes between a biological form of aggression based on adaptation, common in all animal species including humans, and a malignant form not based on adaptation, which appears to occur only in human beings. GómezJarabo (1999) calls this malignant aggression violence and limits the term aggression to describe that which serves an adaptive purpose or is beneficial.

For Gómez-Jarabo, then, aggression is a natural form of behaviour based on biology; one that is adaptive, intentional, purposeful and common to the entire animal kingdom. In principle it is seen as a positive and normal response to adverse circumstances within the limits of self-control and at times even justifiable and beneficial to the survival of an individual or an entire species. A certain amount of aggression could in fact be necessary as an act of selfaffirmation when taking initiatives such as establishing one's identity and participating in cooperative and competitive activities. Countless examples of this are found in the animal kingdom: such as defending territory, protection of young and fights between males during the mating season. When correctly channelled, then, aggression appears to be intrinsic to the animal kingdom, designed to ensure the survival of the individual and the species. In the case of humans it is the force that enables a person to be healthily self-assertive and autonomous and to control both the environment and the self.

When the use of that force goes beyond what is acceptable, however, aggression becomes violence, which is always unacceptable in the well-founded view of Gómez-Jarabo (1999). Violence is therefore a negative, excessive and inappropriate form of behaviour when used to destructive ends and should therefore be condemned. It could be described as pathological; a malignant biological transformation resulting from mental dysfunction that is specific to humans. This view coincides with the first definition of the word violence in the dictionary of the Spanish Royal Academy: "the quality of being violent", meaning "not in a natural state, context or mode of action" - in other words, I would add, behaviour that is pathological and connected to situations of abuse and violent domination.
This notwithstanding, violent behaviour is subject to change, at least in theory, though this requires changing both individuals and their environment. How can this be done? Using methods based on biology (cognitive behavioural therapy and psycho-pharmacological treatment) and by developing social skills (programmes designed to promote security, structure and bonds with other people).

The lack of consensus on aggression probably stems primarily from the plethora of definitions, models and classifications found in scientific literature (see, for example, Ramírez 1998, 2000, 2003). The term "aggression" is so ambiguous and is used so widely and in such a general, imprecise manner that it seems almost impossible to establish a unified and comprehensive definition for it. Such a state of terminological confusion is not surprising considering that over 100 definitions exist. Aggression is one of the words Pascal referred to as "primitive" and which many people understand without needing a definition. Similarly, the term "violence" is somewhat ambivalent, as judge Arturo Beltrán (1999) skilfully demonstrates in his study of the term in Spain's Criminal Code. Although violence is always identified as reprehensible and punishable, its definition is sometimes limited to vis physica or a physical attack on a person (unlike the vis moralis involved in intimidation). Another area of doctrine presents ample jurisprudence in which the concept of violence includes mere intimidation. Some even extend the concept to objects - vis in rebus - in cases where the freedom of individuals is also affected (for example, changing a lock or digging a ditch to prevent access to a home) or a person being drugged and subsequently robbed (using "date rape" drugs).

In short, aggression can be viewed as a category that covers a whole range of forms of behaviour intended to cause harm. These forms of behaviour may represent psychobiological adjustments useful for the struggle for life, as part of what is to some extent positive competition. From this angle, aggression plays a protective and organisational role that can help to generate the impetus needed to define a social structure and achieve lasting peace. On other occasions, however, aggression can be expressed out of context, without necessary self-control and produce destructive consequences (Nelson 
and Trainor, 2007). This is what some prefer to call violence.

Far from being an unequivocal, one-dimensional term, aggression is a heterogeneous and complex phenomenon with a great variety of meanings. This variability is reflected in the fact that the term describes many phenomena that, although similar in appearance, actually differ in their functions and antecedents, genetic and neural mechanisms, and the external factors by which they are triggered. It is therefore a socioemotional process that is multifaceted (with differing antecedents, manifestations and consequences) and dynamic (continuously evolving, both ontogenetically and phylogenetically) (Gendreau and Archer 2005). As a result, it is not enough to agree on a general definition without first establishing the existence of specific functional types of aggression, each with different regulatory mechanisms and determinants (Bandura 2001).

Most of these manifold existing classifications of human aggression - in our view, too many - can be divided into those based on the form it takes or how it is expressed, and those that focus more on its function or goal. The following examples are in no way exhaustive (for a more detailed description, see Ramirez and Andreu, 2003).

In 1961 Buss proposed a model based on direction: active aggression (an action, such as hitting another person) and passive aggression (a lack of action, such as not avoiding - allowing - someone to fall over a cliff). Studies on the latter have appeared frequently in recent years in the context of indirect forms of aggression (Richardson and Hammock 2011; Richardson and Warren 2007). A similar approach is used in the distinction between externally directed aggression (directed towards others) and internally directed aggression (directed at oneself), the most extreme form of which is suicide. Other models focus on the form that the aggression takes (Buss 1961; Underwood 2003): physical aggression, involving direct contact between those involved; verbal aggression, involving language and non-verbal (non-physical) aggression, which can be expressed symbolically or by using different facial expressions and body language.

Some models are based on the way in which aggression is triggered in social interactions.
For example, a distinction is made between (a) direct aggression, which includes acts usually occurring during direct, physical or verbal social interaction, that is, in face-to-face confrontation; and (b) indirect aggression, in which, on the contrary, there is no direct contact involved in the social exchange between aggressor and victim. Instead, the harm typically observed in this kind of aggression is inflicted via an intermediary - a person or an object - and in a subtle way or even later in time. It is associated with impulsive behaviour rather than aggressive behaviour. Indirect aggression overlaps with two other categories: social aggression and relational aggression (Crick et al. 2002), which involve manipulation of social relations to damage friendship, reputation or social status. Relational aggression is based on damage to social ties, while social aggression additionally includes negative facial expressions and gestures (Gendreau and Archer 2005).

If we apply the same criteria to antisocial behaviour, two other forms of aggression can be identified - overt and covert - as suggested by Little and Hawley (2002) and these are, to a certain degree, comparable to direct and indirect aggression. This can be seen in the significant correlation between overt-direct and relationalindirect - aggression, so much so that the authors refer to overt and relational aggression and classify direct and indirect aggression as subtypes. The authors have thus identified four primary dimensions to aggression: overt-direct, relational-indirect, instrumental-offensive and reactive-defensive.

Another classification method is based on function, purpose or goal. In terms of the reasons for inflicting aggression, a distinction can be made between hostile aggression (based simply on the pleasure of causing harm) and instrumental aggression (aimed at achieving non-aggressive goals) (see Bandura 1973; Buss 1961; Feshbach 1964). Other classifications distinguish between reactive and proactive aggression (Dodge 1991; Dodge and Coie 1987) or between impulsive and premeditated aggression (Barratt and Felthous 2003; Coccaro et al. 1989; Linnoila et al. 1983). While different authors have developed different models with different terms, this system of classification reveals certain parallels between these types of aggressive behaviour. An analysis of empirical 
data from applied studies in our laboratory reveals a significant statistical link between hostile, reactive and impulsive aggression, on the one hand, and instrumental, proactive and premeditated aggression, on the other (Ramírez 2009).

These hostile or instrumental and reactive or active dichotomies are not always synonymous: both instrumental and hostile aggression can be proactive in that they may arise without provocation. Similarly, a person can be hostile without displaying the emotional anger associated with reactive aggression (Vitaro and Brendgen 2005). However, they suggest a shared general focus:

1. A socio-cognitive type of aggression which emphasises an instrumental-premeditatedproactive-controlled-calculated-offensive-predatory-in cold blood focus associated with a positive view of aggression. The following characteristics are included in this category: instrumental, premeditated and proactive aggression.

2. A second type - emotional - which emphasises a hostile-impulsive-reactive-uncontrolled-retaliatory-defensive-emotional-hot blooded focus associated with a negative view of aggression. Its characteristics are hostile, impulsive and reactive aggression.

For the sake of conceptual clarity in categorisations of aggression, then, efforts should be made to standardise terminology and certain methods of measurement, or at least reduce the numbers involved (Ramírez 2009).

\section{Some acts of aggression have multiple motives}

For an analytical model of aggression to be a proper and appropriate psychological construct, it must be sufficiently reliable and valid. This is often problematic given the difficulty of precisely establishing the motives and multiple social, cultural and professional factors that influence the different models of human aggression discussed above.

Certain authors (Bushman and Anderson 2001) believe that traditional opposition-based classifications, useful though they were in developing the first theories on aggression, are no longer relevant today, as they do not admit that acts of aggression may be motivated by multiple factors. This is likely to be true. In certain circumstances an act of aggression can fall under two or more categories simultaneously. For example, in many cases the act of aggression can be both verbal (criticism of an absent individual) and non-verbal (through gestures or by ignoring or excluding them) or even be a physical act (against that person's property, a co-species or inter-species other or even an inanimate object). This interdependency makes it considerably more difficult to decide in which category a given act of aggression should fall. Other acts of aggression can be caused by a wide variety of factors: cigarette smoke, unpleasant odours, high temperatures and even disturbing scenes have all been proven to increase hostility in a person or the level of punishment meted out to others in laboratory experiments. Natural observation has confirmed this phenomenon: violent crime tends to increase in hot temperatures, which can also contribute to family disorders (Berkowitz 1989).

In addition to the above, a single motive can lead to different kinds of aggression. In many laboratory experiments, for example, participants are asked to punish others as a form of instrumental aggression. At the same time, however, they may inflict a much more intense level of punishment than is strictly necessary out of a real desire to inflict harm upon the other person. Here, a hostile element combines with the instrumental in a single aggressive act.

Frequently, many acts of aggression arise from unclear and multiple motives, combined with numerous contributing factors. According to Barratt and Felthous (2003), 40 per cent of people commit either mostly impulsive or mostly premeditated acts, while the remaining 60 per cent - the majority, in other words - commit acts that are a mixture of both. A good example of this is revenge, which can be described as a combination of both types of aggression spontaneous-reactive (hostile) and instrumental. Revenge is clearly linked to rage - the idea being to inflict as much suffering as possible upon the offender in an attempt to avenge oneself upon that person without regard for possible consequences for oneself or society. There may also be a cold determination to "educate the 
offender" using a form of moralising aggression aimed at upholding justice. As this revenge requires justification, educational moral assistance is sought to save the revenge from being viewed as a new transgression. Overlapping criteria therefore tend to be the norm rather than the exception in different categories of aggression.

We argue nevertheless that while an exhaustive analysis of the form an act of aggression takes may appear to be over simplistic (in relation to the above-mentioned idea that most aggressive acts are based on a combination of motives) and ineffective when establishing a model (see Bushman and Anderson 2001), distinguishing the type of aggression in a sufficiently reliable way becomes very useful and important - essential, in fact - in determining the resulting effect and particularly the function, motive or purpose of the aggressor and his or her possible treatment. Different types of aggression stem from different sources; engender different emotional, cognitive and behavioural consequences and have different implications when diagnosing, preventing or treating them (Kempes et al. 2005).

\section{The importance of categorising aggression when making legal decisions}

Court rulings on criminal behaviour are based on an interpretation of the acts in the framework of rules of social conduct. "The state of mind that the prosecution, to secure a conviction, must prove that a defendant had when committing a crime; criminal intent or recklessness" (Garner, 1999, p.999) is legally known as mens rea, which in Latin means a guilty mind. A criminal act (actus reus) can only be defined as such in the presence of an essential component, a criminal motive, intention or purpose on the part of the perpetrator. In a criminal trial motive is crucial; investigators use motives to generate lists of suspects and both the prosecutor and defence rely on motive to convince a jury of a person's innocence or guilt. Therefore, the key to distinguishing whether an act is criminal, accidental or committed on a legal, non-criminal basis (self-defence, for example) is the criminal intention of the offender - the guilt factor referred to in legal terminology as mens rea.

The legal process is at the heart of the debate on human self-control. To what extent can individuals control their behaviour in a given situation? To what extent are acts of aggression premeditated (that is, planned, intentional or proactive) and to what extent are they committed without thinking (impulsively or reactively)? To what extent are aggressive acts unconscious and to what extent do they show a lack of concern as to possible consequences for oneself and others? Mens rea presupposes that individuals are capable of acting and anticipating possible consequences and are conscious of what they are doing. Our western-based ones justice systems are founded on the assumption that people not suffering from mental illness can control their behaviour. Criminal law is thus based on the idea that criminals' acts are premeditated and that they make a choice: if there is no choice, there is no criminal. Impulsivity, on the other hand, could affect one's ability to distinguish between right and wrong or between reality and fantasy and therefore has a bearing on the guilt or innocence of the accused. If impulsivity is unconscious, then knowing what causes an act of aggression could be useful in determining the degree to which a person exercises free will - in other words, whether a premeditated act is more culpable than an impulsive one (Barratt and Felthous 2003).

Independently of the above, it is important not to confuse impulsivity - a psychiatric term with a lack of premeditation, a legal term. While the legal implications remain unclear, an impulsive crime is not synonymous with an unpremeditated one. Acts of impulsive aggression and unpremeditated crimes share some similarities such as environmental triggers. Psychiatry, however, cannot define the legal and moral implications of impulsive behaviour. Distinctions that are important in psychiatric categories may have no legal relevance - impulsivity, for example, could be an important factor in both premeditated and unpremeditated crimes. Without examining the legal distinction between impulsivity and premeditation in detail, while motive remains a crucial element in the judicial process and in determining innocence or guilt, an analysis of different legal systems and contexts - for example, the work of Bushman 
and Anderson (2001) - would suggest that the law is focusing less and less on motive to determine what type of homicide has been committed, for example.

Using modern neuroimaging techniques it is possible to examine decision-making mechanisms in depth by observing the human brain in action. What is free will, one may wonder, in an individual predisposed to rage or violent behaviour? Could personal responsibility disappear in the face of organic changes such as genetic variations or brain damage? Reducing the space for free will have surprising effects (Bordel et al. 2006). It would appear then that neuroscience has begun to cast doubt on the idea of free will and our subsequent responsibility for our actions.

Common mental elements of criminal acts - intent, malice, premeditation and recklessness - presume conscious awareness and the ability to form a wish to act or to anticipate the possible consequences of the action, or both. In this regard, distinguishing between impulsive and premeditated aggression in terms of mens rea is important in forensic psychiatry, although quantifying whether a psychological intent amounts to a criminal intent and how much conscious anticipation establishes a mental state of recklessness may be difficult in individual cases (Barratt and Felthous 2003).

To summarise, an analysis of functional types of aggression would seem particularly useful in cases where criminal responsibility must be established.

\section{Categorising aggression is also important for prediction}

Aggression theories and models provide more powerful explanations as they describe the ways in which different personalities may be associated with aggression. According to Douglas and Ogloff (2003), risk assessment experts stress the importance of clearly defining the type of aggression in all communications among relevant institutions. Addressing both relatively stable internal mechanisms (differences in personality traits among individuals) and external situational variables will enable researchers to make more accurate predictions when defining behavioural trends. Improved knowledge of how they interact will provide clearer information on individual differences in aggression and personality dimensions that may forecast different propensities towards aggression, regardless of the specific processes operating and whether they result from prior learning or genetic influences.

For example, a meta-analysis (Bettencourt et al. 2006) demonstrates that the interaction between personality variables and the level of provocation influences aggressive behaviour. Specific personality traits, such as anger and irritability, are sensitive to provocation, predicting a tendency to be aggressive only when provoked, after reflection, or being inclined to irritability and aggressiveness in very different situations, including under relatively neutral conditions, that is, without needing to be provoked, insulted, irritated or frustrated.

Clearly, there are individual differences in the probability of frustration leading to an attack. More than fifty years ago Block and Martin (1955) suggested that ego strength using terminology specific to the era - could mediate the effects of frustration: children with low ego strength reacted more aggressively than others with high ego strength when prevented from obtaining what they wanted, presumably because they were less capable of regulating their emotional responses when faced with frustration. More recently, 25 years ago, Strube et al. (1984) identified another set of individual qualities that could also affect the probability of aggressive reactions, through their influence on the strength of self-control. By frustrating test subjects by asking them to solve unsolvable puzzles, researchers found that the frustration effect was more readily seen in participants with Type A personality (given their lower ability for selfcontrol), than those with a Type B personality. Interestingly, the interaction between personality types and frustration was more apparent when the participants engaged in hostile (that is, emotional) aggression, than in the case of premeditated instrumental aggression. These results concur with the theory of planned behaviour, whereby the prediction of intentions is much more accurate in hostile aggression than in instrumental aggression (Berkowitz 1989).

To improve the prediction of future adjustment problems we also need to distinguish between reactive and proactive aggression. For 
example, distinguishing the type of aggression is very useful in coronary disease research. Individuals with a Type A personality, who are prone to coronary diseases, tend to express more anger, aggressive behaviour, self-destructive tendencies and hostility. According to Vitaro et al. (2002), a key variable in the increased vulnerability to coronary diseases is the coldblooded interpersonal form of hostility, whereas the warm-blooded neurotic intra-psychic form does not predict this vulnerability (Bettencourt et al. 2006). It also appears that a Type A personality has a particular inclination to exhibit a warm-blooded type of aggressive behaviour.

Reactive and proactive aggressions are associated with different forms of development in terms of delinquency, especially during adolescence. One type of development, known as the overt pathway, begins with aggressive behaviour classed as proactive aggression (for example, annoying others or starting fights), followed by frequent physical fighting and ending in violence. Another type, the covert pathway, forms of behaviour such as lying, stealing or vandalism, which are also part of the proactive instrumental form of aggression. A third type, the authority conflict pathway, is characterised in the beginning by stubbornness, defiance and disobedience, which, with time, is followed by truancy and running away from home. Given the nature of the specific forms of behaviour present, proactive aggressiveness may predict early physical aggressiveness (Vitaro et al. 2002), which could ultimately increase the risk of overt and covert criminal delinquency (Miller and Lynam 2006). This tendency towards future delinquency and crime can perhaps be explained, at least partly, because this type of boy has more friends than those with reactive personalities and probably because these friends also tend to be proactively aggressive. Therefore, for proactively aggressive adolescents it is not easy to distance themselves from fights given their weak self-control; it seems that they attract aggression (Vitaro and Brendgen 2005).

In contrast, reactive aggressiveness pushes the individual to retaliate, which is a predictor of aggressive responses within a negative cycle (Crick and Dodge 1996) and authority conflict (given the emotional confrontations between reactively aggressive people and authority figures). Vitaro (2002) and Vitaro and Brendgen (2005) also suggest that reactive aggression may be associated with anxiety and attention deficit disorder, somatic ailments and hypochondria. Reactively aggressive people are more unstable, excitable, hostile and temperamental and often have no friends. Their relationships are ultimately more violent than those of proactively aggressive people. Unlike proactive aggression, however, reactive aggression does not predict subsequent criminal behaviour (Vitaro and Brendgen 2005). Therefore, identifying individuals with personalities tending towards specific types of aggressiveness helps to predict possible future undesirable behavioural patterns.

\section{Categorising aggression is also important for its affective control and treatment}

Identifying people with specific aggressive tendencies also provides access to a range of intervention strategies for preventing aggressive acts, facilitating appropriate treatment and reducing future interpersonal violence. This is because different prognoses and treatments require differing information processing mechanisms. It is therefore important to define clearly the different types of aggression, since they may be associated with various potential predictors, undiagnosed medical problems, psychiatric comorbidity, environmental specificities and so on.

Intervention programmes vary according to the type of aggression. A practical intervention has been described to prevent and control aggression based on the following dichotomy: affiliation substitution using more positive social skills and the teaching of effective mechanisms for confronting sources of conflict, frustration or threats. While threats and appropriate incentives may modify proactive aggression, the best therapy for impulsive aggression appears to involve changing the most striking features of habitual behaviour that cause vulnerable people to resort to provocation. Another example can be found in the much debated theme of violence on television (Ramírez 2007a): special efforts should be made to protect the individuals most 
vulnerable to models presented in the media from the potentially harmful effects of violent scenes.

While anger-control techniques seem appropriate for treating hostile reactively aggressive people, programmes for treating proactively and instrumentally aggressive patients seek to change reinforcement contingencies so that aggression does not receive positive reinforcement. Though some authors accept that cognitive behavioural therapy is a good technique for instrumental aggression they are very sceptical about the use of simple psychological techniques against reactive hostile aggression. In their opinion this type of aggression requires pharmacotherapy (Haller and Kruk 2006).

In brief, profound knowledge of the correlates of the different categories of aggression is crucial in achieving maximum clinical effectiveness in using the most appropriate intervention programmes for the prevention, assessment, control or treatment of aggressiveness as treatments differ according to the type of aggression. It is therefore necessary for researchers to reach a consensus on the correct categorisation of aggression, since without conceptualisation and a taxonomy based on a sound theoretical basis the diagnosis of aggressive disorders would lack a solid foundation and, ultimately, its clinical value would be regrettably much reduced (Parrot and Giancola 2007).

\section{Conclusion}

In conclusion, aggression is a heterogeneous construct with substantial semantic overlap with terms for many different forms of behaviour categorised by the intention to harm others. This explains the large number of classifications proposed in the scientific literature, according to the form, mode and function of aggression. In our opinion, it is more than advisable to establish an appropriate categorisation of the different functions and aims of aggression, especially if further research is soon expected to be conducted into the mechanisms and functions of aggression and into the diagnosis, prevention and treatment of abnormalities and lack of control. We must never forget that biology does not condemn humanity to violence. In fact, the opposite is true: the better our knowledge of human biology, the more capable we will be of controlling violence. As the Seville Statement on Violence (Adams et al. 1986, p.59) concludes: "The same species who invented war is capable of inventing peace. The responsibility lies with each of us".

Translated from Spanish

\section{Notes}

*The author wishes to thank José Luis Diaz and Roberto E. Mercadillo, organisers of the Twenty-fifth International Colloquium on the Brain and Aggression in Mexico, where this work was presented, as well as the institutions that made it possible: Harvard University, where he drafted the text in the Kennedy School of Government during a sabbatical period, and the
Universidad Complutense de Madrid and the Ministry of Science and Technology of Spain for funding research projects PR 189/92-4340, PB 94-0297 and BSO 2001/1224.

\section{References}

Adams, D., Barnett, S. A., Bechtereva, N. P., Carter, B. F., Delgado, J. M. R., Díaz, J. L., Eliasz, A., Genovés, S., Ginsburg,
B. E., Gröbel, J., Ghosh, S. K., Hinde, R. A., Leakey, R. E., Malasi, T. H., Ramírez, J. M., Mayor Zaragoza, F., Mendoza,
D. L., Nandy, A., Scott, J. P. AND Wahlstrom, R., 1986. "The Seville Statement on Violence", Cahiers du mouvement universel de la 
responsabilité scientifique, 5 , 51-59.

Bandura, A., 1973. Aggression: $a$ social learning analysis. Englewood Cliffs, NJ: Prentice Hill.

BAndura, A., 2001. "Social cognitive theory: an agentic perspective", Annual review of psychology, 52, 1-26.

Barratt, E. S. and Felthous, A. R., 2003. "Impulsive versus premeditated aggression: implications for mens rea decisions", Behavioral sciences and the law, 21 (5), 619-630.

Beltrán, A., 1999. “Violencia y derecho. [Violence and law]", In: Gómez-Jarabo, G., ed. Violencia: antitesis de la agresión. [Violence: antithesis of aggression]. Valencia: Promolibro, 339-358.

Berkowitz, L., 1989. "Frustrationaggression hypothesis: examination and reformulation", Psychological bulletin, 14 (1), 59-73.

Bettencourt, B. A., Talley, A., Benjamin, A. J. and Valentine, J., 2006. "Personality and aggressive behavior under provoking and neutral conditions: a meta-analytic review", Psychological Bulletin, 132, 5, 751-777.

Block, J. And Martin, B. C. (1955). "Predicting the behavior of children under frustration", Journal of abnormal and social psychology, 51 (2), 281-285.

Bordel, S., Guingouain, G. And Somat, A., 2006. "Objective and subjective responsibility in a judicial context", Swiss journal of psychology, 65 (4), 227-235.

Bushman, B. And Anderson, C., 2001. "Is it time to pull the plug on hostile versus instrumental aggression dichotomy?", Psychological review, 108 (1), 273-279.

Buss, A., 1961. The psychology of aggression. New York: Wiley.

Coccaro, E. F., Siever, L. J., Klar, H. M., Maurer, G., Cochrane, K., Cooper, T. B., Mohs, R. C. And DAvis, K. L., 1989. "Serotonergic studies in patients with affective and personality disorders. Correlates with suicidal and impulsive aggressive behaviour', Archives of general psychiatry, 46 (7), 587-599.

Crick, N. R. And Dodge, K. A., 1996. "Social informationprocessing mechanisms in reactive and proactive aggression", Child development, 67 (3), 993-1002.

Crick, N. R., Grotpeter, J. K. And Bigbee, M. A., 2002. "Relationally and physically aggressive children's intent attributions and feelings of distress for relational and instrumental peer provocations", Child Development, 73 (4), 1134 1142.

Dodge, K., 1991. "The structure and function of reactive and proactive aggression", In: D. Pepler, and K. Rubin, eds The development and treatment of childhood aggression. Hillsdale, NJ: Erlbaum, 201-218.

Dodge, K. And Coie, J., 1987. "Social information-processing factors in reactive and proactive aggression in children's peer groups", Journal of personality and social psychology, 53 (6), 1146-1158.

Dominic, J., Parrott, Peter, R. and Giancola, P. R., 2007.

"Addressing 'The criterion problem' in the assessment of aggressive behavior: development of a new taxonomnic system",

Aggression and violent behavior, 12 (3), 280-299.

Douglas, K. S. and Ogloff, J. R. P., 2003. "Multiple facets of risk for violence: the impact of judgmental specificity on structured decisions about violence risk", International journal of forensic mental health, 2 (1), 19-34.

FeshbaCH, S., 1964. "The function of aggression and the regulation of the aggressive drive", Psychological review, 71, 257-272.

Fromm, E., 1973. The anatomy of human destructiveness. New York: Holt, Rinehart and Winston.
Garner, B. A., ed., 1999. Black's law dictionary. (7th edn). St Paul, MN: West Group.

Gendreau, P. L. And Archer, J., 2005. Subtypes of aggression in humans and animals. In: R. E. Tremblay, W. W. Hartup, and J. Archer, eds Developmental origins of aggression. New York: Guilford, 25-46.

Gómez-Jarabo, G., 1999. Violencia: antitesis de la agresión. [Violence: antithesis of aggression]. Valencia: Promolibro.

Haller, J. And KruK, M. R., 2006. "Normal and abnormal aggression: human disorders and novel laboratory models", Neuroscience \& biobehavioral reviews, 30 (3), 292-303.

Kempes, M., Matthys, W., De Vries, H. and Van Engeland, H., 2005. "Reactive and proactive aggression in children. A review of theory, findings and the relevance for child and adolescent psychiatry", European journal of psychiatry, 14 (1), 11-19.

Linnoila, M., VirkKunen, M., Scheinin, M., Nuutila, A., Rimon, R. And Goodwin, F. K., 1983. "Low cerebrospinal fluid 5-

hydroxyindoleacetic acid concentration differentiates impulsive from non impulsive violent behavior", Life sciences, 33 (26), 2609-2614.

Little, T. and Hawley, P., 2002. Pathways of the forms and functions of aggression during adolescence. 15 th World Meetings of the ISRA, Montreal.

Miller, J. D. And Lynam, D. R., 2006. "Reactive and proactive aggression: similarities and differences", Personality and individual differences, 41 (8), 1469-1480.

Nelson, R. J. and Trainor, B. C., 2007. "Neural mechanisms of aggression", Nature reviews Neuroscience, 8 (7), 536-546.

Ramírez, J. M., 1991. "Similarities in attitudes toward interpersonal aggression in Finland, Poland, and 
Spain", Journal of social psychology, 13, 737-739.

Ramírez, J. M., 1993.

"Acceptability of aggression in four Spanish regions and a comparison with other European countries", Aggressive behavior, 19 (3), 185-197.

Ramírez, J. M., 1998.

"Aggression", In: G. Greenberg, and M. M. Haraway, eds Comparative psychology: a handbook. New York: Garland, 625-634.

Ramírez, J. M., 2000. Agresión: un enfoque psicobiológico. [Aggression: a psychobiological approach]. Valencia: Promolibro.

Ramírez, J. M., 2003. Human aggression. Madrid: Centreur.

RAmírez, J. M., 2007a. “Televisión y violencia [Television and violence]", Revista Latinoamericana de psicología, 39 (2), 327-349.

Ramírez, J. M., 2007b. "Justification of aggression in several Asian and European countries with different religious and cultural background", International journal of behavioral development, 31 (1), 9-15.

Ramírez, J. M., 2009. "Some dichotomous classifications of aggression according to its function", Journal of organisational transformation and social change, 6 (2), 85-101.

Ramirez, J.M And Andreu, J. M., 2003. "Aggression's typologies", International review of social psychology, 16 (3), 125-141.

Richardson, D. S. AND Hammock, G. S., 2011. "Is it aggression? Perceptions of and motivations for passive and psychological aggression", In: J. P. Forgas, A. W. Kruglanski, and K. D. Williams, eds The psychology of social conflict and aggression. Thirteenth Sydney Symposium of Social Psychology, 16-18 March 2010.

Richardson, D. S. And Warren, P., 2007. Is passive aggression a unique category? Twenty-third CICA, Augusta, Georgia, 11-14 January.
Strube, M. J., Turner, C. W., Cerro, D., Stevens, J. And Hinchey, F., 1984. "Interpersonal aggression and the type A coronaryprone behaviour pattern: a theoretical distinction and practical implications", Journal of personality and social psychology, 47 (4), 839-847.

Underwood, M. K., 2003. Social aggression among girls. New York: Guildford Press.

Vitaro, F. and Brendgen, M., 2005. Proactive and reactive aggression. A developmental perspective. In: R. E. Tremblay, W. W. Hartup, and J. Archer, eds Developmental origins of aggression. New York: Guilford, 178-201.

Vitaro, F., Brendgen, M. And Tremblay, R. E., 2002. "Reactively and proactively aggressive children: antecedent and subsequent characteristics", Journal of child psychology and psychiatry, 43 (4), 495-505. 